\section{Infection control CPD for dental professionals}

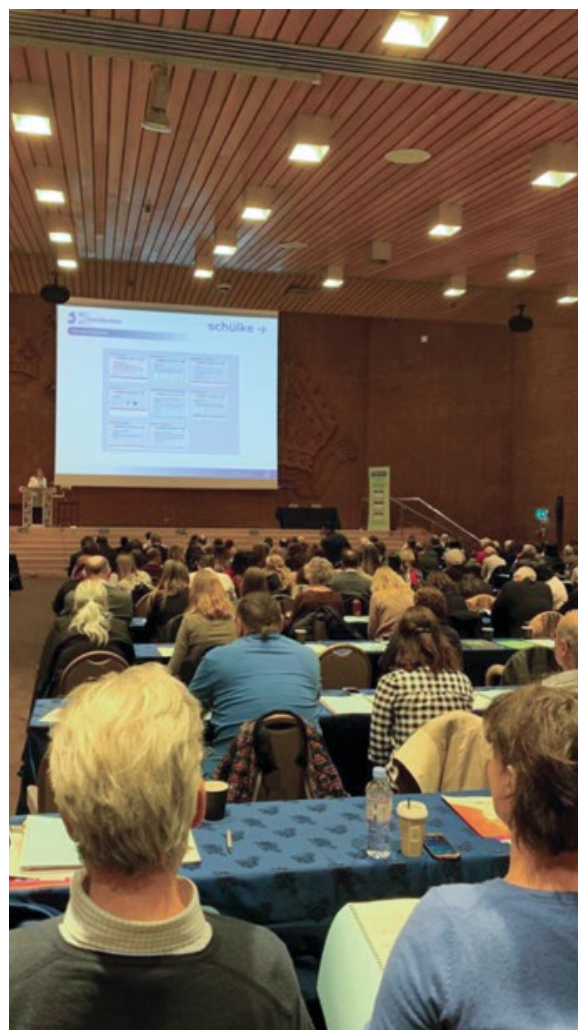

Vanessa Hoole - Field Sales Manager, schülke $\mathrm{UK}$, is delivering infection control training to potentially thousands of dental professionals attending Core CPD Update conferences 2019, organised by Professional Conferences.

The GDC recommends five core areas in which dental professionals should carry out $\mathrm{CPD}$ and this series of ten conferences (each one attended by $200-450$ delegates) is taking place across the UK. The aim is to ensure the dental team is up to date in core areas, as well as helping satisfy the GDC's requirements for verifiable CPD.

Due to Vanessa's considerable experience in infection prevention, she was asked by Professional Conferences to cover this key area. Vanessa's training entitled 'Delivering excellence ... Preventing risks' encompasses infection control, regulations, legal aspects, microbiology, ethics, staff training and cleaning, disinfection and sterilisation.

For more information on schülke UK, call 0114254 3500, visit www.schuelke.com or emailmail.uk@schuelke.com.

https://www.proconferences.com/ dental-conferences/

01923859626

\title{
Clean water without chemicals
}

Dental treatment systems offer ideal conditions under which V biofilm can form and micro-organisms such as Pseudomonas, Legionella and Cryptosporidium can flourish. These micro-organisms can be exposed to the patient via the cooling water, mouth rinsing water and aerosol exposure. Hygowater from Dürr Dental ensures the service water in your practice always meets the same stringent requirements as drinking water. This standard is consistent with the advice given by the Robert Koch Institute.

Water-carrying systems in treatment units can still, however, harbour various micro-organisms, which can colonise and form a biofilm which adheres to the inner walls of the unit. To ensure optimum safety micro-organisms must be reduced to a minimum and biofilm permanently removed from hoses and pipes.

Hygowater is a system that promises safe and reliable service water processing. It fulfils all the legal requirements for water hygiene as well as satisfying the meticulous standards demanded by the German Drinking Water Ordinance as well as meeting the requirements for a Class I medical device.

The compact unit is extremely easy to operate. The unique combination of filtration and electrolysis prevent biofilm formation and thus minimises infection risks to both patients and practitioners. As well as being good for the safety of the practice, it's also great for the environment, as long-term drinking water quality is ensured without the use of any chemical additives.

\section{Dentist designs green brush with detachable head}

Dr M's Oral Brush is the first $100 \%$ recyclable manual toothbrush with a detachable head. It was designed by British dentist Dr Suki Murbay who came up with the idea for the brush during a 'lightbulb moment'.

Dr Murbay, who was born in Newcastle upon Tyne, qualified from the University of Manchester in 1993, practised in Newcastle and later worked in Hong Kong as a Clinical Assistant Professor in operative dentistry. While in Hong Kong, Dr Murbay achieved a worldwide patent for a dental wear simulator. He has since set up a company for his own branded dental merchandise and has just started trading.

Dr M's Oral Brush (intended to clean the oral cavity, not just the teeth) is made from polyethylene terephthalate glycol-modified PETG and the bristles from high-quality Dupont nylon. The brush is approved by the Oral Health Foundation. It comes as a complete annual set of one handle and four heads, so that the head can be replaced every three months. The detachable heads can be pushed on and off and are very easy to replace. If a patient is too vigorous in brushing their teeth the head will detach, which will minimise the potential for tooth abrasion cavities and loss of sound tooth tissue.

Dr M's Oral Brush is patient friendly and environmentally friendly. Future plans include an oral hygiene set comprising a handle, a brush head, a floss attachment, an interdental cleaning attachment and a tongue cleaner.

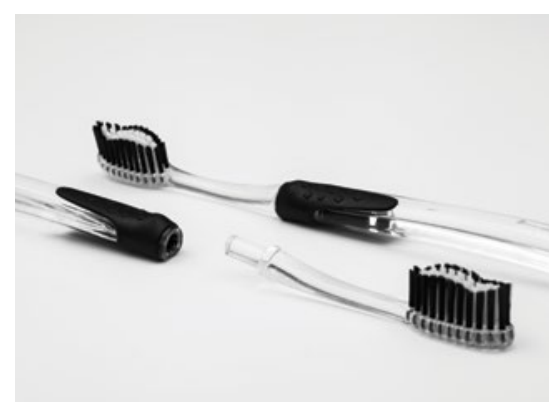

Parties interested in distributing and selling Dr M's Oral Brush should contact info@oral-brush.com or call 07881822334.

A website is under construction at www. oral-brush.com. 